\title{
Principios para el tratamiento de infecciones odontogénicas con distintos niveles de complejidad*
}

\author{
Drs. IGNACIO VELASCO M. ${ }^{1,2}$, REINALDO SOTO N.,3
}

1 Residente, Departamento de Cirugía Bucal y Maxilofacial. Universidad de Puerto Rico. Puerto Rico, EE.UU.

2 Profesor, Departamento de Cirugía Bucal y Maxilofacial. Universidad de los Andes. Santiago, Chile.

3 Profesor, Unidad de Morfología. Universidad de los Andes. Santiago, Chile.

\begin{abstract}
Principles for the treatment of odontogenic infections with different levels of complexity
\end{abstract}

Odontogenic infections are one of the main causes of consultation in dental practice. These, affect individuals of all ages and are responsible for the majority of antibiotic prescriptions in the field of dentistry. Odontogenic infections are generally underestimated in terms of morbidity and mortality, although the incidence and severity have decreased dramatically over the past 70 years. However, odontogenic infections can have varying degrees of severity and even some can be quite complex and need emergency care in a hospital setting under a specialist in Oral and Maxillofacial Surgery. Odontogenic infections are commonly the result of pericoronitis, caries with pulp exposure, periodontitis or complication of a dental procedure. The literature contains various principles and approaches for odontogenic infections therefore the objective of our review is to establish a simplified manner based on the current literature, the principles that the clinician should follow to face odontogenic infections with different levels of complexity.

Key words: Odontogenic infection, odontogenic abscess, antibiotics.

\section{Resumen}

Las infecciones odontogénicas son una de las principales causas de consulta en la práctica odontológica. Estas afectan a individuos de todas las edades y son responsables de la mayoría de las prescripciones de antibióticos en el campo de la odontología. Las infecciones odontogénicas son generalmente subestimadas en términos de morbilidad y mortalidad, aunque su incidencia y severidad han bajado drásticamente en los últimos 70 años. Sin embargo, estas infecciones pueden presentar distintos grados de severidad e incluso algunas pueden ser bastante complejas y necesitar una atención de emergencia en un ambiente hospitalario bajo un especialista en Cirugía Bucal y Maxilofacial. Las infecciones odontogénicas son comúnmente el resultado de una pericoronaritis, caries con exposición pulpar, periodontitis o la complicación de un procedimiento dental.

* Recibido el 29 de mayo de 2012 y aceptado para publicación el 12 de julio de 2012.

Los autores no refieren conflictos de interés.

Correspondencia: Dr. Ignacio Velasco M.

Department of Oral and Maxillofacial Surgery. School of Dental Medicine, University of Puerto Rico. PO Box 365067. San Juan PR 00936-5067 iavelasco@miuandes.cl, ignacio.velasco@upr.edu 
Existen en la literatura diversos principios y planes de tratamiento para las infecciones odontogénicas, por lo que el objetivo de nuestra revisión es establecer de una manera simplificada en base a la literatura actual los principios que el clínico debería seguir para enfrentar infecciones odontogénicas con distintos niveles de complejidad.

Palabras clave: Infección odontogénica, absceso odontogénico, antibióticos.

\section{Introducción}

Las infecciones odontogénicas (IOs) son una de las principales causas de consulta en la práctica odontológica. Estas afectan a individuos de todas las edades y son responsables de la mayoría de las prescripciones de antibióticos en el campo de la odonto$\operatorname{logía}^{1}$. Estas IOs pueden presentar distintos grados de severidad e incluso algunas pueden ser bastante complejas y necesitar atención de emergencia en un ambiente hospitalario bajo un especialista en Cirugía Bucal y Maxilofacial.

Las IOs son generalmente subestimadas en términos de morbilidad y mortalidad, si bien la incidencia y severidad han bajado drásticamente en los últimos 70 años. Históricamente, la posibilidad de que un absceso de origen dental se propagara generando sepsis y la muerte ha sido conocido desde la antigüedad, aunque el rol de las bacterias en este proceso no fue descubierto hasta el siglo XX. Cuando los certificados de defunción (Londres, Inglaterra) comenzaron a mostrar las causas de muerte a comienzos del 1600 's, las infecciones de origen dental ocupaban el sexto lugar ${ }^{2}$.

En 1940, Ahsbel Williams publicó una serie de 31 casos de angina de Ludwig, la gran mayoría de origen dental, donde el $54 \%$ de los pacientes fallecieron ${ }^{3}$. Tres años más tarde Guralnick y col, publicaron el primer estudio prospectivo en el campo de infecciones de cabeza y cuello, en el cual la mortalidad de la angina de Ludwig fue reducida a un $10 \%{ }^{4}$. Esta considerable disminución de la mortalidad no fue por el uso de antibióticos, sino por el manejo inicial de la vía aérea seguido por el drenaje quirúrgico de los espacios anatómicos comprometidos. Actualmente la mortalidad de la angina de Ludwig, en conjunto con el tratamiento quirúrgico y la administración de antibióticos está en el rango de $4-10 \%{ }^{5,6}$.

La odontología en las últimas décadas ha realizado un gran trabajo en la prevención y manejo temprano de las IOs. Tanto el odontólogo como el especialista en cirugía deben estar preparados en la identificación y manejo inicial de las patologías infecciosas de la cavidad bucal. Sin embargo, para el manejo de las IOs más complejas es importante que el clínico tenga actualizados sus conocimientos de anatomía quirúrgica, microbiología y farmacología.

El objetivo de esta revisión es presentar y discutir en base a la literatura actual los principios básicos para el adecuado manejo y tratamiento de IOs con distintos niveles de complejidad.

\section{Principios para el tratamiento de infecciones odontogénicas}

Peterson y col, propusieron un protocolo con 8 pasos para el manejo de las $\mathrm{IOs}^{7}$. Hemos modificado este protocolo simplificándolo en los 7 siguientes pasos, los cuales discutiremos de manera ordenada y fundamentada con la literatura actual:

I. Determinar la etiología y severidad de la infección.

II. Evaluar los antecedentes médicos y sistema inmune del paciente.

III. Decidir el lugar de atención.

IV. Tratamiento quirúrgico.

V. Soporte médico y nutricional.

VI. Elegir y prescribir el antibiótico adecuadamente.

VII. Evaluar al paciente periódicamente.

\section{Determinar la etiología y severidad de la infección}

Una completa historia clínica y examen físico, le permitirá al clínico identificar tres factores en este paso: etiología y espacios anatómicos comprometidos, estadío de la infección y compromiso de la vía aérea ${ }^{8}$.

\section{Etiología y espacios anatómicos comprometidos}

Las IOs son comúnmente el resultado de una pericoronaritis, caries con exposición pulpar, periodontitis o la complicación de un procedimiento dental. La pieza dentaria causal de estas IOs es variable, aunque las infecciones más severas provienen del segundo o tercer molar mandibular ${ }^{9,10}$.

Los espacios anatómicos de cabeza y cuello involucrados deben ser identificados y clasificados según el potencial compromiso de la vía aérea y/o de estructuras vitales como el mediastino, corazón o contenido craneal (Figuras 1 y 2). Flynn y col, desarrollaron para las IOs una escala de severidad (ES) en el cual le asignan un valor numérico de 1 a 4 por el compromiso leve, moderado, severo y extremo de los espacios anatómicos, respectivamente $(\text { Tabla } 1)^{11}$. Este valor numérico está en estrecha re- 


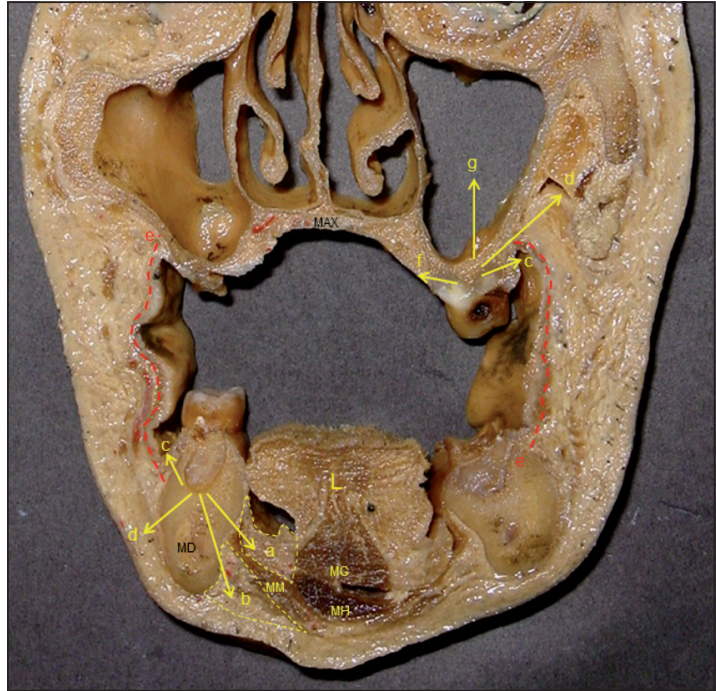

Figura 1. Corte coronal de cadáver que muestra las posibles vías de propagación de las IOs en espacios anatómicos de cara y cuello (flechas). a: espacio sublingual; b: espacio submandibular, MM: músculo milohioideo, MG: músculo geniogloso, MH: músculo genihioideo, L: lengua, MD: mandíbula; c: espacio submucoso vestibular; d: espacio geniano; e: músculo buccinador; f: espacio submucoso palatino; g: seno maxilar, MAX: maxilar.

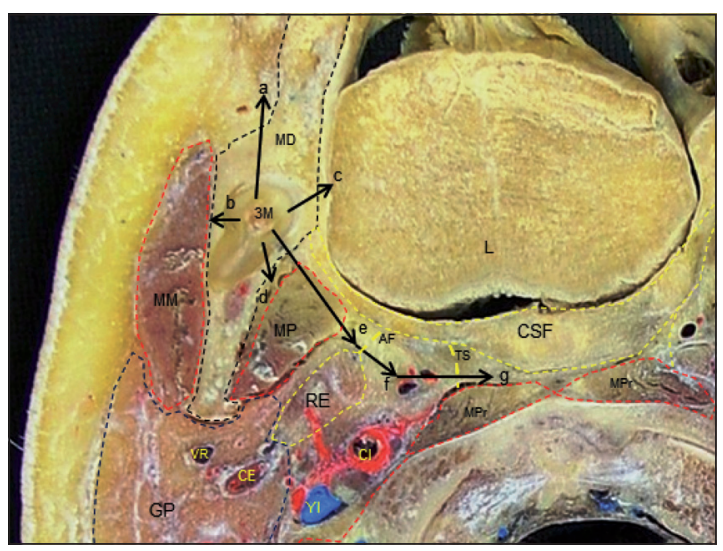

Figura 2. Corte transversal de cadáver que muestra las posibles vías de propagación de IOs desde molares mandibulares hacia espacios anatómicos de cara y cuello (flechas). MD: mandíbula, 3M: tercer molar, a: espacio submucoso vestibular, b: espacio submaseterino, MM: músculo masetero, c: espacios sublingual y submandibular, $\mathrm{d}$ : espacio pterigomandibular, MP: músculo pterigoideo medial, e: espacio pterigofaríngeo, RE: ramillete estíleo (de Riolano), AF: aleta faríngea, f: espacio retroestileo, YI: vena yugular interna, CI: arteria carótida interna, TS: tabique sagital, g: espacio retrofaríngeo, MPr: músculos prevertebrales, GP: glándula parótida, VR: vena retromandibular, CE: arteria carótida externa, CSF: músculo constrictor superior de la faringe, L: lengua.
Tabla 1. Escala de severidad (ES) según los espacios anatómicos comprometidos ${ }^{8,11}$

\begin{tabular}{|c|c|}
\hline Escala de severidad & Espacio anatómico \\
\hline $\begin{array}{l}\text { Escala de severidad= } 1 \\
\text { Riesgo leve para vía aérea y/o } \\
\text { estructuras vitales }\end{array}$ & $\begin{array}{l}\text { Huesos maxilares } \\
\text { Subperióstico } \\
\text { Submucoso vestibular } \\
\text { Submucoso palatino } \\
\text { Geniano }\end{array}$ \\
\hline $\begin{array}{l}\text { Escala de severidad }=2 \\
\text { Riesgo moderado para vía aérea } \\
\text { y/o estructuras vitales }\end{array}$ & $\begin{array}{l}\text { Submandibular } \\
\text { Submentoniano } \\
\text { Sublingual } \\
\text { Pterigomandibular } \\
\text { Submaseterino } \\
\text { Temporal } \\
\text { Interpterigoideo }\end{array}$ \\
\hline $\begin{array}{l}\text { Escala de severidad }=3 \\
\text { Riesgo severo para vía aérea y/o } \\
\text { estructuras vitales }\end{array}$ & $\begin{array}{l}\text { Pterigofaríngeo } \\
\text { Retrofaríngeo } \\
\text { Pterigopalatino } \\
\text { Pretraqueal }\end{array}$ \\
\hline $\begin{array}{l}\text { Escala de severidad }=4 \\
\text { Riesgo extremo para vía aérea } \\
\text { y/o estructuras vitales }\end{array}$ & $\begin{array}{l}\text { Mediastino } \\
\text { Intracraneal } \\
\text { Prevertebral }\end{array}$ \\
\hline
\end{tabular}

La ES de un paciente se determina sumando los valores numéricos de todos los espacios comprometidos, basándose en los hallazgos clínicos e imagenológicos.

lación con el riesgo que posee el espacio anatómico de comprometer la vía aérea y estructuras vitales, en la Tabla 2 se muestra en aspectos generales los límites, contenidos y comunicaciones de estos espacios anatómicos ${ }^{12}$.

Si el paciente posee compromiso de más de un espacio, se realiza la sumatoria de estos valores numéricos, por ejemplo un paciente con una infección odontogénica (IO) que compromete el espacio geniano $(\mathrm{ES}=1)$ y el espacio submandibular $(\mathrm{ES}=2)$, tendría una ES total de 3. Flynn y col, pudieron correlacionar esta ES y el recuento de leucocitos inicial con el tiempo de hospitalización en un $66 \%$ de 37 casos de IOs con distintos grados de severidad ${ }^{11,13}$.

\section{Estadio de la infección}

Es importante que durante la anamnesis se determine el inicio del cuadro inflamatorio y el dolor, para compararlos con los signos y síntomas actuales en relación a la inflamación, dolor, fiebre, trismus y compromiso de la vía aérea ${ }^{8}$. Las IOs pueden cursar 3 etapas antes de su resolución, las características generales están descritas en la Tabla $3^{14}$.

La primera etapa es la inoculación que dura 2-3 días, consiste en un proceso inflamatorio de los espacios anatómicos comprometidos de consistencia suave y levemente doloroso. Entre los días 2 y 5 el proceso infeccioso se puede propagar de manera 
Tabla 2. Limites, contenido y relaciones de los espacios anatómicos comprometidos ${ }^{12}$

\begin{tabular}{|c|c|c|c|c|}
\hline $\begin{array}{l}\text { Espacio } \\
\text { anatómico }\end{array}$ & $\begin{array}{c}\text { Bordes } \\
\text { (sup, inf, post, ant, lat, med) }\end{array}$ & Contenido & Comunicaciones & $\begin{array}{l}\text { Posible diente } \\
\text { causal }\end{array}$ \\
\hline Geniano & $\begin{array}{l}\text { Reborde infraorbitario } \\
\text { Borde inf. mandíbula } \\
\text { Borde ant. Musc. masetero } \\
\text { Nariz, ángulo oral }\end{array}$ & $\begin{array}{l}\text { Conducto parotideo } \\
\text { Vasos faciales } \\
\text { Vasos transversos faciales } \\
\text { Paquete neurovascular IOr } \\
\text { Cuerpo adiposo mejilla }\end{array}$ & $\begin{array}{l}\text { E. pterigomandibular } \\
\text { E. temporal }\end{array}$ & $\begin{array}{l}\text { Canino maxilar } \\
\text { Premolares maxilares } \\
\text { Molares maxilares } \\
\text { Premolares mand. }\end{array}$ \\
\hline $\begin{array}{l}\text { Submandi- } \\
\text { bular }\end{array}$ & $\begin{array}{l}\text { Musc. milohioideo } \\
\text { Hueso hioides } \\
\text { Vientre post. Musc. digástrico } \\
\text { Vientre ant. Musc. digástrico }\end{array}$ & $\begin{array}{l}\text { Glandula submandibular } \\
\text { Vasos faciales } \\
\text { Linfonodos } \\
\text { Ramo MM nervio VII }\end{array}$ & $\begin{array}{l}\text { E. sublingual } \\
\text { E. submentoniano } \\
\text { E. pterigomandibular } \\
\text { E. pterigofaríngeo }\end{array}$ & Molares mand. \\
\hline $\begin{array}{l}\text { Submento- } \\
\text { niano }\end{array}$ & $\begin{array}{l}\text { Musc. milohioideo } \\
\text { Fascia cervical prof. } \\
\text { Hueso hioides } \\
\text { Borde inf. mandíbula } \\
\text { Vientres anteriores M. digástricos }\end{array}$ & $\begin{array}{l}\text { Vena yugular anterior } \\
\text { Linfonodos }\end{array}$ & $\begin{array}{l}\text { E. submandibular } \\
\text { E. sublingual }\end{array}$ & Anteriores mand. \\
\hline Sublingual & $\begin{array}{l}\text { Mucosa oral } \\
\text { Musc. milohioideo } \\
\text { Hiato submandibular } \\
\text { Superficie lingual mandíbula } \\
\text { Musc. lengua }\end{array}$ & $\begin{array}{l}\text { Glándula sublingual } \\
\text { Conducto submandibular } \\
\text { Nervio lingual } \\
\text { Vasos sublinguales } \\
\text { Nervio XII }\end{array}$ & $\begin{array}{l}\text { E. submandibular } \\
\text { E. submentoniano } \\
\text { E. pterigofaríngeo } \\
\text { E. pterigomandibular }\end{array}$ & $\begin{array}{l}\text { Premolares mand. } \\
\text { Molares mand. }\end{array}$ \\
\hline $\begin{array}{l}\text { Pterigo- } \\
\text { mandibular }\end{array}$ & $\begin{array}{l}\text { Musc. pterigoideo lateral } \\
\text { Borde inf. mandíbula } \\
\text { Parótida } \\
\text { Musc. buccinador } \\
\text { Rama mandibular } \\
\text { Musc. pterigoideo medial }\end{array}$ & $\begin{array}{l}\text { V3 nervio trigemino } \\
\text { Vasos alveolares inferiores }\end{array}$ & $\begin{array}{l}\text { E. submandibular } \\
\text { E. sublingual } \\
\text { E. pterigofaríngeo } \\
\text { E. submaseterino } \\
\text { Orbita }\end{array}$ & $\begin{array}{l}\text { Terceros molares } \\
\text { mand. }\end{array}$ \\
\hline $\begin{array}{l}\text { Submasete- } \\
\text { rino }\end{array}$ & $\begin{array}{l}\text { Arco cigomático } \\
\text { Borde inf. mandíbula } \\
\text { Borde post. mandíbula } \\
\text { Borde ant. Musc. masetero }\end{array}$ & Vasos maseterinos & $\begin{array}{l}\text { E. temporal } \\
\text { E. pterigomandibular }\end{array}$ & Molares mand. \\
\hline Temporal & $\begin{array}{l}\text { Linea temporal superior } \\
\text { Arco cigomático } \\
\text { Borde ant. Musc. temporal } \\
\text { Borde post. Musc. temporal }\end{array}$ & $\begin{array}{l}\text { Vasos temporales superf. } \\
\text { Vasos temporales prof. } \\
\text { Ramo temporal VII } \\
\text { Nervios temporales prof. }\end{array}$ & $\begin{array}{l}\text { E. interpterigoideo } \\
\text { E. pterigomandibular } \\
\text { E. submaseterino }\end{array}$ & $\begin{array}{l}\text { Molares maxilares } \\
\text { Molares mand. }\end{array}$ \\
\hline $\begin{array}{l}\text { Interpteri- } \\
\text { goideo }\end{array}$ & $\begin{array}{l}\text { Ala mayor esfenoides } \\
\text { Pterigoideo lateral } \\
\text { Pterigoideo medial }\end{array}$ & $\begin{array}{l}\text { Vasos maxilares } \\
\text { V3 nervio trigemino } \\
\text { Plexo venoso pterigoalveolar }\end{array}$ & $\begin{array}{l}\text { E. temporal } \\
\text { E. pterigopalatino } \\
\text { E. pterigomandibular } \\
\text { E. pterigofaríngeo }\end{array}$ & Molares maxilares \\
\hline $\begin{array}{l}\text { Pterigopa- } \\
\text { latino }\end{array}$ & $\begin{array}{l}\text { Ala mayor del esfenoides } \\
\text { Proceso pterigoideo } \\
\text { Tuberosidad maxilar } \\
\text { Lámina perpendicular palatino }\end{array}$ & $\begin{array}{l}\text { V2 nervio trigemino } \\
\text { Ganglio pterigopalatino } \\
\text { Arteria maxilar y ramas }\end{array}$ & $\begin{array}{l}\text { Cavidad craneal } \\
\text { E. interpterigoideo } \\
\text { E. temporal } \\
\text { Orbita }\end{array}$ & Molares maxilares \\
\hline $\begin{array}{l}\text { Pterigofa- } \\
\text { ríngeo }\end{array}$ & $\begin{array}{l}\text { Base del cráneo } \\
\text { Parótida } \\
\text { Musc. pterigoideo medial } \\
\text { Faringe }\end{array}$ & $\begin{array}{l}\text { Nervio IX, XII } \\
\text { Tejido celular laxo }\end{array}$ & $\begin{array}{l}\text { E. pterigomandibular } \\
\text { E. retrofaríngeo } \\
\text { E. sublingual } \\
\text { E. submandibular }\end{array}$ & $\begin{array}{l}\text { Terceros molares } \\
\text { mand. }\end{array}$ \\
\hline $\begin{array}{l}\text { Retrofarín- } \\
\text { geo }\end{array}$ & $\begin{array}{l}\text { Base del cráneo } \\
\text { Región prevertebral } \\
\text { Faringe } \\
\text { Tabique sagital }\end{array}$ & $\begin{array}{l}\text { Linfonodos retrofaringeos } \\
\text { Tejido celular laxo }\end{array}$ & $\begin{array}{l}\text { E. pterigofaríngeo } \\
\text { E. prevertebral } \\
\text { Cavidad craneal } \\
\text { E. retroesofágico }\end{array}$ & $\begin{array}{l}\text { Terceros molares } \\
\text { mand. }\end{array}$ \\
\hline
\end{tabular}

Sup: superior, inf: inferior, post: posterior, ant: anterior, lat: lateral, med: medial, musc: músculo, IOr: infraorbitario, MM: marginal mandibular, VII: facial, IX: glosofaríngeo, XII: hipogloso, V2: división maxilar, V3: división mandibular, superf: superficiales, prof: profundos, E: espacio, mand: mandibulares. 
Tabla 3. Estadíos de la $\mathrm{IO}^{8,14}$

\begin{tabular}{|llll|}
\hline Características & Inoculación & Flegmón (celulitis) & Absceso \\
\hline Tiempo de evolución & $0-3$ días & $2-7$ días & $>5$ días \\
Dolor & Leve-moderado & Severo & Moderado-severo \\
\hline Tamaño & Pequeño & Grande & Pequeño \\
Localización & Difusa & Difusa & Localizado \\
Consistencia a palpación & Suave & Pétrea o indurada & Fluctuante \\
Fluido del tejido & Edema & Serosanguinolento, pus $(+/-)$ & Pus $(+)$ \\
Grado de severidad & Leve & Severo & Moderado-severo \\
Bacterias predominantes & Aerobios & Mixta & Anaerobios \\
\hline
\end{tabular}

difusa con consistencia indurada o pétrea, y muy doloroso a la palpación constituyendo el flegmón o celulitis. La siguiente etapa que puede desarrollarse sobre los 5 días es el absceso, donde se definen mejor los bordes y la consistencia central de la inflamación se hace más blanda y fluctuante. La etapa final de las IOs puede ser la resolución mediante el drenaje espontáneo o quirúrgico, o la muerte del paciente por el compromiso de la vía aérea y/o la difusión del proceso infeccioso hacia estructuras vitales ${ }^{14}$.

\section{Compromiso de la vía aérea}

La causa más frecuente de muerte en los casos reportados de IOs es la obstrucción de la vía aérea ${ }^{6}$. Por lo tanto, el clínico debe evaluar este aspecto en los primeros momentos cuando se enfrenta a una infección de cabeza y cuello. Es de suma importancia identificar ciertos signos y síntomas cuando existe compromiso de espacios anatómicos de riesgo moderado o más (Tabla 1).

El trismus es un signo obvio de sospecha de una IO. Una apertura bucal que ha disminuido $20 \mathrm{~mm}$ o más en un corto periodo de tiempo con dolor severo es considerada una infección de espacios anatómicos perimandibulares hasta que se demuestre lo contrario $^{8}$. No obstante, pese al trismus, el clínico debe evaluar la presencia de disfagia y visualizar la orofaringe en busca de un posible proceso infeccioso.

En casos de obstrucción parcial de la vía aérea existirán sonidos anormales en la respiración como lo es el estridor y la sibilancia por el paso turbulento del aire a través de las vías respiratorias. El paciente en estos casos adquiere una posición especial inclinando la cabeza hacia anterior o moviendo el cuello hacia el hombro del lado contrario para enderezar la vía aérea y mejorar la ventilación ${ }^{8}$. Una saturación de oxígeno bajo $94 \%$ en un paciente previamente sano es un signo que indica insuficiente oxigenación a los tejidos, esto acompañado de signos clínicos de obstrucción parcial es una indicación inmediata para establecer una vía aérea segura ${ }^{8}$. Exámenes complementarios como la tomografía axial computada (TC) nos permiten visualizar el compromiso de espacios anatómicos profundos y la estenosis de la vía aérea por un proceso infeccioso con hasta un $89 \%$ de precisión ${ }^{10}$.

En el caso de una obstrucción total de la vía aérea, esta corresponde a una emergencia quirúrgica y se debe realizar la intubación endotraqueal de urgencia si es posible, o una traqueostomía o cricotiroidotomía ${ }^{7}$.

\section{Evaluar los antecedentes médicos y sistema inmune del paciente}

Existen ciertas condiciones médicas que pueden interferir con la función del sistema inmune, lo cual es esencial en la defensa del paciente contra las IOs.

La diabetes mellitus (DM) es la enfermedad más prevalente que afecta al sistema inmune ${ }^{15}$. El principal factor etiológico en la DM, que conduce a una disfunción en el sistema inmunológico es la hiperglicemia ${ }^{15,16}$. Todos los principales tipos celulares involucrados en el sistema inmune se ven afectados. Los neutrófilos tienen alterada su función en la adhesión, quimiotaxis y fagocitosis. Esto da como resultado una defensa menos eficaz contra un ataque microbiano ${ }^{17-19}$. Los monocitos y macrófagos en el paciente diabético liberan mayor cantidad de citoquinas proinflamatorias, así también está aumentada la producción de metaloproteinasas de la matriz, tales como la colagenasa ${ }^{20,21}$. Esto crea un desequilibrio que es perjudicial para la contención de las infecciones de cabeza y cuello. El estado hiperglicémico además puede conducir a una disminución en la proliferación de fibroblastos y la síntesis de colágeno, impidiendo el recambio de tejido y la reparación de heridas ${ }^{21}$. Diversos estudios 
han demostrado que la DM es un factor de riesgo para las infecciones periodontales ${ }^{22}$.

Los corticoides cuando son usados en periodos prolongados ya sea en condiciones cutáneas, enfermedades autoinmunes, asma y otras enfermedades inflamatorias, pueden aumentar las posibilidades de que alguna infección bacteriana o fúngica ocurra. Los corticoides estabilizan las membranas de las células inmunocompetentes disminuyendo la respuesta inmune ${ }^{23}$. Pacientes con trasplante de órganos son tratados de manera crónica con corticoides, así también con medicamentos inmunosupresivos como las ciclosporinas ${ }^{23}$.

Pacientes que presenten neoplasias malignas pueden poseer compromiso del sistema inmune ${ }^{24}$. El mecanismo por lo que esto sucede no está claro. Se cree que un tipo de células T-reguladoras que han sido encontradas infiltrando tumores, son potentes inmunosupresores del sistema inmune y además promueven la progresión del cáncer al tener la habilidad de limitar la inmunidad antitumoral y de promover la angiogénesis ${ }^{24}$. Además, la quimioterapia contra el cáncer suprime directamente la respuesta inmune, por lo que todos los pacientes sometidos a quimioterapia con menos de un año de evolución están inmunocompremetidos ${ }^{8}$.

Otras condiciones que pueden alterar la respuesta inmune son el alcoholismo, enfermedad renal crónica y la malnutrición ${ }^{8}$. El rol del síndrome de inmunodeficiencia adquirida (SIDA) en las IOs no es claro, ya que los estudios no muestran una mayor incidencia de IOs severas en estos pacientes ${ }^{25}$. Sin embargo, un número significativo de pacientes con SIDA desarrollan neutropenia como consecuencia de la infección retroviral directa, el uso de medicamentos antirretrovirales, infecciones sistémicas y los mecanismos autoinmunes alterados ${ }^{26}$. Además, los neutrófilos de pacientes con SIDA tienen su función bactericida y quimiotáctica deficiente ${ }^{27,28}$. En consecuencia, se ha propuesto que el deterioro de la función de los neutrófilos, junto con defecto en la síntesis de inmunoglobulinas son causas importantes en el aumento del riesgo de infecciones bacterianas en pacientes con enfermedad avanzada por $\mathrm{VIH}^{29}$. Asimismo, los pacientes con SIDA cuando padecen de una IO cursan una estadía hospitalaria más prolongada ${ }^{30}$.

\section{Decidir el lugar de atención}

Como mencionamos anteriormente las IOs son una de las principales causas de atención odontológica de urgencia. Si bien, no todas van a requerir ser solucionadas en un ambiente hospitalario, es importante determinar algunas de las posibles indicaciones que le señalen al clínico si el paciente va a requerir una admisión hospitalaria.
Una fiebre por mayor de los $38,5^{\circ} \mathrm{C}$ es dañina al incrementar las demandas metabólicas y cardiovasculares más allá de la capacidad de reserva, donde la pérdida de fluidos se ve significativamente aumentada y conlleva a la deshidratación ${ }^{8}$. Pacientes con enfermedades concomitantes, como las antes mencionadas, $u$ otras que requieran estabilización médica y farmacológica serán clara indicación de admisión hospitalaria. Infecciones de espacios anatómicos con ES de 2 o más pueden causar trismus severo, alterando la nutrición del paciente y aún más grave, comprimiendo la vía aérea por inflamación o atentando contra estructuras vitales ${ }^{8}$.

En muchos estudios el recuento inicial de células blancas ha sido un predictor importante en el tiempo de estadía hospitalaria. Leucocitosis por sobre $12.000 / \mathrm{mm}^{3}$ generan un síndrome de respuesta inflamatoria sistémica, un factor importante para determinar que una IO requiere admisión hospitalaria $^{11,13,31}$

Generalmente, muchos de estos pacientes se van a beneficiar al ser admitidos e intervenidos bajo anestesia general debido a la imposibilidad de obtener una adecuada anestesia local, manejo de la vía aérea o por la no cooperación durante el tratamiento, especialmente en niños o pacientes con discapacidades mentales 8 .

Ante la duda es importante recalcar que siempre es mejor admitir al paciente que tratarlo de manera ambulatoria, de esta manera nos aseguramos que esté continuamente monitoreado y bajo la supervisión de un equipo médico multidisciplinario que rápidamente pueda asegurar una vía aérea comprometida.

\section{Tratamiento quirúrgico}

El manejo quirúrgico de las IOs, sin importar su severidad, consta de 2 principios: eliminar el foco etiológico y el vaciamiento quirúrgico de los espacios anatómicos comprometidos con la instalación de un drenaje adecuado.

El foco dental causal debe ser identificado en base a los hallazgos clínicos e imagenológicos. Mediante los conocimientos de anatomía quirúrgica podemos conocer las posibles vías de propagación hacia otras regiones vecinas (Tabla 2, Figuras 1 y $2)^{12}$. La eliminación de la causa ya sea mediante la extirpación pulpar, debridaje, eliminación de tejido necrótico o la exodoncia de los focos dentales se debería realizar lo más pronto posible ${ }^{13}$. Sin embargo, pueden existir algunas posibles contraindicaciones locales que difieran el tratamiento, como un trismus severo o una pericoronaritis aguda supurada, esta última puede causar una infección más severa de regiones profundas. En estos casos el paciente deberá recibir un par de días de terapia antibiótica y antiin- 
flamatoria para controlar y disminuir la infección e inflamación de los tejidos comprometidos.

En lo que respecta al tiempo de vaciamiento quirúrgico de los espacios anatómicos comprometidos, igualmente debería ser abordado de manera agresiva y lo antes posible, como fue descrito inicialmente por William y Guralnick ${ }^{4}$. Este enfoque se basa en el concepto de que el vaciamiento y drenaje quirúrgico temprano anula la propagación de la infección hacia espacios más profundos y severos, incluso si la infección está en un estadío de flegmón. En un estudio prospectivo de 37 pacientes hospitalizados con IOs severas, Flynn y col, realizaron el tratamiento quirúrgico lo antes posible después de la admisión (promedio de $5 \pm 7,5 \mathrm{hrs})^{11}$. En ninguno de sus casos el tratamiento quirúrgico propagó la infección y la necesidad de reoperación ( $8 \%$ de los casos) no fue significativamente diferente para los abscesos o flegmones ${ }^{11}$.

Para realizar el vaciamiento y drenaje quirúrgico es necesario un vasto conocimiento de la anatomía de los espacios topográficos de cabeza y cuello (Tabla 2), el clínico será capaz de usar puntos de referencia anatómicos para abordar estos espacios haciendo pequeñas incisiones estrictamente cutáneas o mucosas, y la disección roma profunda sin la visualización directa del espacio anatómico comprometido $^{8}$. La ubicación de las incisiones debe ser en tejido sano, respetando las estructuras neurovasculares y en áreas cosméticamente aceptables (Figuras 3 y 4$)^{32}$. El sitio de la incisión y la instalación del drenaje se basan en los posibles caminos que puedan seguir las IOs (Figuras 1 y 2) o con el apoyo de una TC preoperatoria que muestre los espacios comprometidos. En esta etapa se pueden obtener muestras para el cultivo microbiano y antibiograma, pero debido a la demora en su obtención (aproximadamente $72 \mathrm{~h}$ ) se justificaría en casos de IOs que afecten múltiples espacios o en pacientes con compromiso del sistema inmune ${ }^{8}$.

Se prefiere la instalación de drenajes que otorguen dos caminos para la emergencia del pus y la irrigación unidireccional de un sitio de la incisión a otro. Se pueden utilizar drenajes tipo Penrose de látex, pero la irrigación de la herida se facilita especialmente con el uso de drenajes tipo Jackson Pratt o un catéter Robinson, que son no colapsables y perforados. La irrigación de los espacios comprometidos remueve restos bacterianos, pus y tejido necrótico de los sitios infectados a medida que se van acumulando. No existe evidencia para decir que la frecuente irrigación empeora el cuadro infeccioso. Aunque, si es importante hacer el aseo periódico del sitio de la incisión y cubrir con un apósito los drenajes extraorales para evitar la contaminación con patógenos hospitalarios. El drenaje debe ser discontinuado una vez que cesa la salida de pus. El pus usualmente deja de fluir de los abscesos entre los días 1 y 3 , este proceso puede ser más extenso cuando nos enfrentamos a flegmones ${ }^{32}$. No obstante, debe tenerse en cuenta que los drenajes tipo Penrose son antigénicos y si son usados por más días de los indicados pueden causar exudados debido a una reacción de cuerpo extraño ${ }^{32}$.

\section{Soporte médico y nutricional}

Las infecciones complejas pueden predisponer a una severa carga fisiológica. Un cuadro febril prolongado puede causar deshidratación, disminuyendo las reservas cardiovasculares y depletar las reservas de glicógeno, cambiando el metabolismo corporal a un estado de catabolismo. El soporte médico para pacientes que padezcan de IOs está compuesto de una adecuada hidratación, nutrición, control del dolor y fiebre ${ }^{8}$.

La adecuada hidratación es uno de los mejores métodos para controlar la fiebre. La pérdida diaria de fluidos por transpiración se ve aumentada hasta en $250 \mathrm{~mL}$ por cada grado de fiebre ${ }^{33}$. Por ejemplo, un paciente de $70 \mathrm{~kg}$ hospitalizado por una IO con una fiebre de $39,4^{\circ} \mathrm{C}$ y con electrolitos en rangos normales, debería recibir aproximadamente $2 \mathrm{~mL} /$ $\mathrm{kg} /$ día de fluidos adicionales sobre la base por cada grado sobre los $37^{\circ} \mathrm{C}$. Además para controlar la fiebre se deberían utilizar ciertos fármacos antipiréticos como el acetaminofén o el metamizol sódico.

El correcto apoyo nutricional constituye uno de los pilares fundamentales en el tratamiento del paciente séptico. Las infecciones desencadenan una respuesta sistémica hormonal, metabólica, circulatoria e inmunológica en cascada que se pone en marcha por la presencia de microorganismos o de sus toxinas. El paciente séptico presenta un estado de hipermetabolismo durante periodos prolongados de tiempo, que vendrá definido por un incremento en el gasto energético basal y en el consumo de oxígeno. En esta situación hay una movilización de carbohidratos, grasas y proteínas para mantener los procesos inflamatorios, la función inmunitaria y la reparación de los tejidos, a expensas de una disminución en la masa corporal magra. En ausencia de un adecuado soporte nutricional, algunos de estos procesos, se pueden ver comprometidos ${ }^{34}$.

\section{Elegir y prescribir el antibiótico adecuadamente}

La adecuada selección del antibiótico y su forma de administración para cada caso clínico puede ser bastante complejo. Al igual que en pasos anteriores deben analizarse ciertos puntos de manera ordenada. Según Flynn \& Halpern, para elegir adecuadamente el antibiótico, se deben evaluar los factores relacio- 


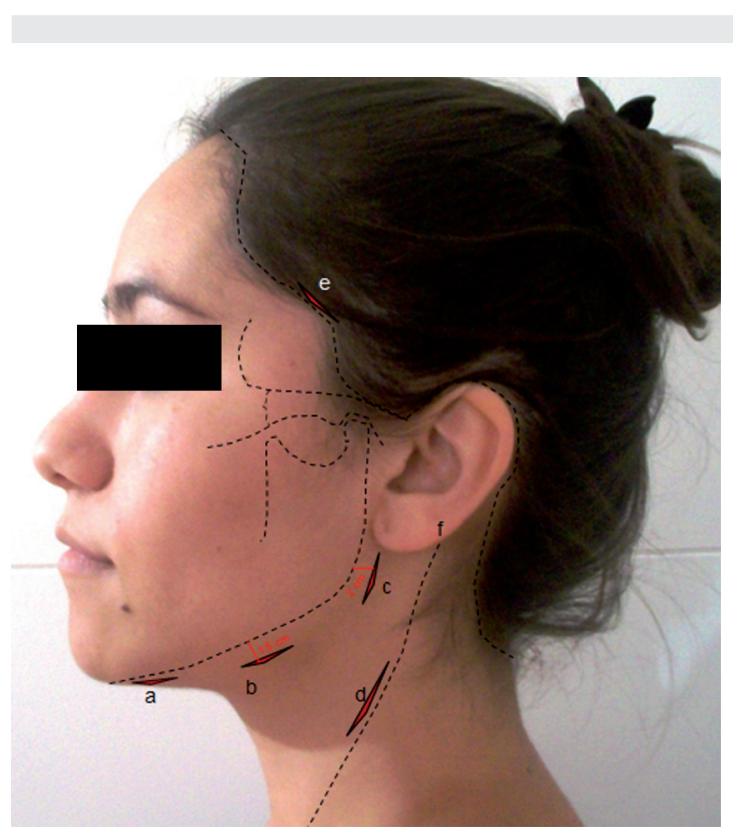

Figura 3. Accesos extraorales para el vaciamiento y drenaje de los espacios anatómicos comprometidos. a: abordaje para espacio submentoniano, b: abordaje para espacio submandibular, submaseterino, pterigomandibular y sublingual (incisión a $1,5 \mathrm{~cm}$ del borde inferior mandibular para evitar daño del ramo marginal mandibular), c: abordaje para espacios pterigomandibular, pterigofaríngeo y retrofaríngeo (a $2 \mathrm{~cm}$ del borde posterior de la rama mandibular para evitar daño del nervio facial), d: abordaje de espacios retrofaríngeo y pterigofaríngeo, e: abordaje de espacios temporal, interpterigoideo, pterigopalatino y submaseterino, f: borde anterior del músculo esternocleidomastoideo.

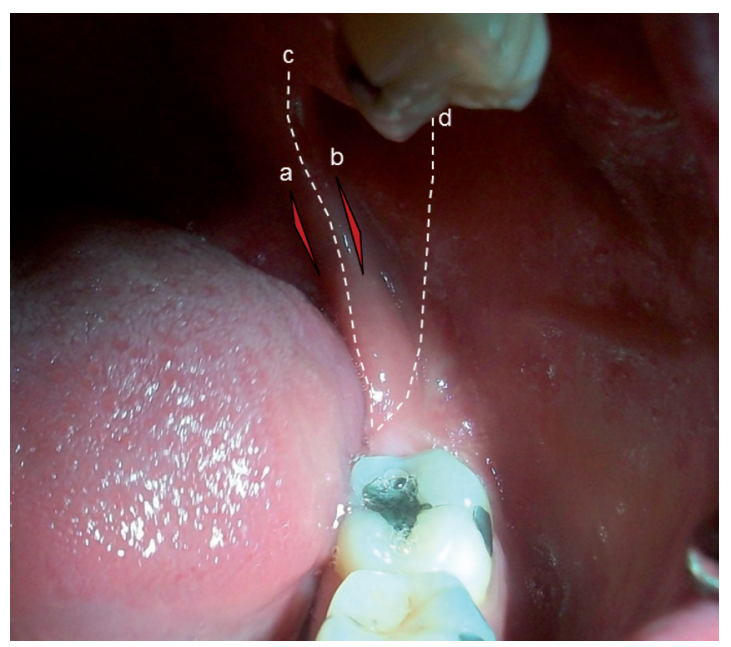

Figura 4. Accesos intraorales para el vaciamiento y drenaje de espacios anatómicos comprometidos. a: abordaje para espacio pterigofaríngeo y retrofaríngeo, b: abordaje para espacio pterigomandibular y submaseterino c: rafe pterigomandibular, d: borde anterior de la rama mandibular. nados del paciente y las consideraciones farmacológicas del antibiótico ${ }^{35}$.

\section{Factores del paciente}

a. Patógenos usuales: El tipo de infección que se presenta puede ser generalmente caracterizado por su causa y ubicación, cada una posee su flora bacteriana característica. Las IOs son generalmente caracterizadas por una combinación de streptococcus anaerobios facultativos y bacterias anaerobias estrictas ${ }^{36}$. Dentro de la especie de los streptococcus viridans (anaerobios facultativos), el grupo streptococcus milleri, que consta del streptococcus anginosus, intermedius y constellatus, son los que se asocian más frecuentemente con flegmones y abscesos bucofaciales. Esto es beneficioso, ya que sólo aproximadamente el 3\% de las cepas de estas especies son resistentes a las penicilinas. Entre los anaerobios, son predominantes los miembros de los géneros peptostreptococcus, prevotella y porphyromonas. Aunque el peptostreptococcus sigue siendo sensible a la penicilina, aproximadamente el $25 \%$ de las cepas de prevotella y porphyromonas son resistentes a la penicilina ${ }^{11}$. Los streptococcus sensibles a la penicilina predominan durante los 3 primeros días de síntomas clínicos, y los Gram-negativos anaerobios estrictos más resistentes aparecen en un número significativo a partir de entonces ${ }^{35}$. Este hecho sugiere la selección de las penicilinas por sobre otro antibiótico en IOs leves y con poco tiempo de evolución. IOs leves que son tratadas de manera ambulatoria responden bien al tratamiento quirúrgico y a la administración oral de penicilinas ${ }^{8}$. En diversos estudios IOs leves han sido tratadas con antibióticos orales empíricamente (Tabla 4), donde no se ha mostrado diferencias significativas entre el uso de amoxicilina, amoxicilina/ ácido clavulánico, clindamicina y cefalexina ${ }^{37-40}$. En todos estos estudios la etiología fue tratada con la extirpación pulpar, exodoncia y drenaje de los espacios anatómicos comprometidos.

Para infecciones severas que requieran una admisión hospitalaria, el antibiótico empírico de elección es más controversial (Tabla 4). Diversos estudios avalan la eficacia de las penicilinas en IOs severas, con bajas tasas de resistencia entre el $4 \%$ y 7\% $0^{41-44}$. En contraparte, existen estudios que evidencian la emergente falla del tratamiento con las penicilinas ${ }^{11,31}$. Flynn y col, en el 2006 obtuvieron un $21 \%$ de falla en el tratamiento con penicilina de 37 IOs severas que requirieron admisión hospitalaria. Flynn recomienda que el antibiótico a usar en IOs severas debiera ser la clindamicina ${ }^{11,31}$, aunque en estos casos severos se justifica obtener un cultivo microbiano y un antibiograma que nos pueda guiar con el tratamiento más efectivo frente a los microbios patógenos presentes. 
Tabla 4. Antibióticos empíricos¥ de elección dependiendo de la severidad, vía de administración (VA), mecanismo de acción (MA), dosis y riesgo durante el embarazo según FDA (RDE), 8,11,31,46

\begin{tabular}{|c|c|c|c|c|c|c|}
\hline $\begin{array}{l}\text { Severidad de la } \\
\text { infección }\end{array}$ & $\begin{array}{l}\text { Antibiótico } \\
\text { de elección }\end{array}$ & $\mathbf{V A}$ & MA & Dosis adulto & Dosis niños & RDE \\
\hline \multirow{7}{*}{$\begin{array}{l}\text { Leve } \\
\text { (ambulatorio) }\end{array}$} & Amoxicilina & Oral & $\mathrm{BC}$ & $500-750 \mathrm{mg} \mathrm{c} / 8 \mathrm{hrs}$ & $20-40 \mathrm{mg} / \mathrm{kg} /$ día en 3 dosis & B \\
\hline & $\begin{array}{l}\text { Amoxicilina/ } \\
\text { ac. clavulánico }\end{array}$ & Oral & $\mathrm{BC}$ & $500-875 / 125 \mathrm{mg} \mathrm{c} / 12 \mathrm{hrs}$ & $25-45 \mathrm{mg} / \mathrm{kg} /$ día en 2 dosis & $\mathrm{B}$ \\
\hline & Cefadroxilo & Oral & $\mathrm{BC}$ & $500 \mathrm{mg}-1 \mathrm{gr} \mathrm{c} / 12 \mathrm{hrs}$ & $30-50 \mathrm{mg} / \mathrm{kg} /$ día en 2 dosis & $\mathrm{B}$ \\
\hline & Clindamicina* & Oral & $\mathrm{BS}$ & $300 \mathrm{mg} \mathrm{c} / 8 \mathrm{hrs}$ & 8-16 mg/kg/día en 3 ó 4 dosis & $\mathrm{B}$ \\
\hline & Metronidazol* & Oral & $\mathrm{BC}$ & $500 \mathrm{mg} \mathrm{c} / 8 \mathrm{hrs}$ & $35-50 \mathrm{mg} / \mathrm{kg} /$ día en 3 dosis & $\mathrm{B}$ \\
\hline & Eritromicina* & Oral & BS & $500 \mathrm{mg} \mathrm{c} / 8 \mathrm{hrs}$ & $30-50 \mathrm{mg} / \mathrm{kg} /$ día en 3 dosis & $\mathrm{B}$ \\
\hline & Claritromicina* & Oral & BS & $250-500 \mathrm{mg} \mathrm{c} / 12 \mathrm{hrs}$ & $15 \mathrm{mg} / \mathrm{kg} /$ día en 2 dosis & $\mathrm{C}$ \\
\hline \multirow{6}{*}{$\begin{array}{l}\text { Moderado-severo } \\
\text { (requiere } \\
\text { admisión } \\
\text { hospital) }\end{array}$} & Penicilina G & EV, IM & $\mathrm{BC}$ & 2-4 mill UI c/6 hrs & 50-100 mil UI/kg/día en 4 dosis & B \\
\hline & $\begin{array}{l}\text { Ampicilina/ } \\
\text { sulbactam }\end{array}$ & EV, IM & $\mathrm{BC}$ & $1,5-3 \mathrm{grc} / 6 \mathrm{hrs}$ & $200-300 \mathrm{mg} \mathrm{c} / 6 \mathrm{hrs}$ & B \\
\hline & Clindamicina* & EV & $\mathrm{BS} / \mathrm{BC}$ & $600-900 \mathrm{mg} \mathrm{c} / 8 \mathrm{hrs}$ & $16-20 \mathrm{mg} / \mathrm{kg} /$ día en 3 ó 4 dosis & B \\
\hline & Ampicilina & EV, IM & $\mathrm{BC}$ & $500 \mathrm{mg} \mathrm{c} / 6 \mathrm{hrs}$ & $12,5 \mathrm{mg} / \mathrm{kg} \mathrm{c} / 6 \mathrm{hrs}$ & B \\
\hline & Cefazolina & EV, IM & $\mathrm{BC}$ & $1 \mathrm{gr} \mathrm{c} / 8 \mathrm{hrs}$ & $25-50 \mathrm{mg} / \mathrm{kg} / \mathrm{día}$ en 3 dosis & B \\
\hline & Metronidazol* & $\mathrm{EV}$ & $\mathrm{BC}$ & $500 \mathrm{mg}-1 \mathrm{gr} \mathrm{c} / 6 \mathrm{hrs}$ & $35-50 \mathrm{mg} / \mathrm{kg} /$ día en 3 dosis & $\mathrm{B}$ \\
\hline
\end{tabular}

${ }^{\ddagger}$ El uso empírico de estos antibióticos debería ser previo a la obtención de un cultivo microbiano y antibiograma. Este cultivo debiera ser obligado en casos severos que afecten pacientes con compromiso del sistema inmune o atentando contra estructuras vitales. *Antibióticos alternativos en pacientes alérgicos a penicilina. EV: endovenoso, IM: intramuscular, BC: bactericida, BS: bacteriostático, B: los estudios en la reproducción en animales no han demostrado un efecto adverso sobre el feto, pero no hay estudios clínicos adecuados y bien controlados hechos en mujeres embarazadas o animales que hayan mostrado un efecto adverso, C: estudios en reproducción animal han mostrado un efecto adverso sobre el feto, pero no hay estudios adecuados y bien controlados en seres humanos, sin embargo, los beneficios potenciales permiten utilizar el fármaco en mujeres embarazadas a pesar de sus riesgos potenciales.

b. Alergia o intolerancia: Una historia de alergia a antibióticos debe ser obtenida durante la anamnesis del paciente consciente o alternativamente de la familia. La alergia a las penicilinas es común y la intolerancia a otros grupos antibióticos como los macrólidos (eritromicina y claritromicina) son también frecuentes ${ }^{35}$.

La elección de otro antibiótico como la clindamicina o el metronidazol puede ser prudente cuando la información anamnésica no está disponible ${ }^{35}$. Las penicilinas son los antibióticos más frecuentemente prescritos para infecciones de la cavidad bucal. No es sorprendente que su uso masificado y muchas veces mal indicado esté asociado con la hipersensibilidad o reacciones adversas. Entre el 1\% y $10 \%$ de los pacientes que en un principio toman penicilinas desarrollan una reacción alérgica ${ }^{45}$. Todos los clínicos deben ser conscientes de la potencial alergia cruzada entre las penicilinas y otros miembros de los $\beta$-lactámicos. Aproximadamente el 10\% a 15\% de los pacientes alérgicos a la penicilina también son alérgicos a las cefalosporinas ${ }^{45}$. Una historia de reacción adversa o la intolerancia a un antibiótico, como la fototoxicidad con las tetraciclinas o la colitis asociada a antibióticos con la clindamicina, impediría su utilización y debería buscarse otra alternativa antibiótica ${ }^{35}$.

c. Compromiso del sistema inmune: El paciente inmunocomprometido es menos capaz de eliminar a las bacterias patógenas. Se deberían utilizar antibióticos con acción bactericida en vez de bacteriostático siempre que sea posible ${ }^{35}$. Los antibióticos bactericidas suelen interferir ya sea con la síntesis de la pared celular, lo que provoca lisis, o con la síntesis del ácido nucleico, que detiene los procesos vitales. Los antibióticos bacteriostáticos interfieren con la síntesis de proteínas, deteniendo el crecimiento y su multiplicación. Algunos antibióticos, como la clindamicina son bacteriostáticos en dosis bajas y bactericidas en dosis más altas ${ }^{35}$.

d. Condiciones especiales: Ciertas condiciones temporales como son el embarazo y la infancia, son aspectos importantes que pueden alterar la selección del antibiótico. En los niños se deben evitar las tetra- 
ciclinas (menores de 12 años), debido a que puede causar tinciones intrínsecas en los dientes permanentes y las fluoroquinolonas, debido a la potencial condrotoxicidad en los cartílagos de crecimiento ${ }^{35}$. El uso de antibióticos durante el embarazo implica una evaluación de riesgo-beneficio. Es necesario conocer las distintas categorías de riesgo según la Food and Drug Administration (FDA) para los antibióticos durante el embarazo ${ }^{46}$. La gran mayoría de los antibióticos con espectro de acción contra los patógenos bucales, como las penicilinas, cefalosporinas, metronidazol y clindamicina están en la categoría B (Tabla 4), y su uso se justificaría frente a una IO.

\section{Factores farmacológicos en la selección del antibiótico}

a. Espectro de acción: La consideración farmacológica más importante en la selección del antibiótico es si es eficaz contra los posibles microrganismos patógenos ${ }^{35}$. Es importante conocer el espectro de acción de todas las familias de antibióticos y la susceptibilidad de las bacterias patógenas usuales a estos, para elegir el antibiótico empírico más adecuado o en base a los resultados del antibiograma para los casos más complejos (Tabla 4).

b. Distribución del antibiótico en los tejidos: Aunque los abscesos no son cavidades vasculares, algunos antibióticos pueden penetrar en estos espacios. El antibiótico que mejor penetra un absceso es la clindamicina, la concentración de la clindamicina en el absceso alcanza el $33 \%$ de la concentración sérica $^{47}$. Este hecho podría explicar en parte la gran utilidad de la clindamicina en las IOs. La penetración del antibiótico en los huesos maxilares es otra importante consideración, especialmente en la osteomielitis ${ }^{47}$. Los antibióticos que mejor penetran o incluso se acumulan en el hueso son las tetraciclinas, clindamicina y las fluoroquinolonas. La capacidad de un antibiótico para llegar al líquido cerebroespinal, o para cruzar la barrera hematoencefálica, es primordial en el tratamiento de infecciones que amenazan el sistema nervioso central, como en la real o inminente trombosis del seno cavernoso ${ }^{48}$. Los antibióticos que pueden alcanzar niveles terapéuticos en el líquido cerebroespinal son las penicilinas, cefalosporinas, fluoroquinolonas, vancomicina y metronidazol ${ }^{48}$.

c. Farmacocinética: La eficacia de algunos antibióticos, tales como las fluoroquinolonas y aminoglucósidos son dependientes de la concentración, mientras que otros antibióticos, tales como los $\beta$-lactámicos y la vancomicina son dependientes del tiempo. En los antibióticos dependientes de la concentración, la eficacia se determina por la relación de la concentración plasmática del antibiótico con la concentración mínima inhibitoria (CMI), esta es la concentración del antibiótico requerida para matar a un determinado porcentaje de las cepas patógenas de una especie en particular, por lo general el 50\% o 90\%. En los antibióticos dependientes del tiempo, es necesario mantener la concentración plasmática por encima de la CMI por lo menos el $40 \%$ del intervalo de dosificación ${ }^{35}$. Es necesario conocer en los antibióticos que dependen del tiempo, la vida media de eliminación en el plasma para determinar el adecuado intervalo de administración.

\section{Evaluar al paciente periódicamente}

Los pacientes con IOs leves son tratados de manera ambulatoria mediante la eliminación del foco etiológico dental junto con el drenaje de los espacios anatómicos comprometidos. El primer control postoperatorio de estos pacientes debiera ser a las $48 \mathrm{hrs}$, para discontinuar el drenaje y evaluar la mejoría o empeoramiento del cuadro infeccioso, permitiendo decidir el próximo paso a seguir8.

Las IOs severas que requieran admisión hospitalaria requerirán continua monitorización bajo un equipo médico multidisciplinario y controles postoperatorios diarios por no menos de $72 \mathrm{hrs,} \mathrm{donde} \mathrm{los}$ signos clínicos de mejoría debieran ser evidentes, como la disminución de la inflamación, cese del drenaje, baja en el recuento de células blancas y reducción de la obstrucción de la vía aérea. Se debe determinar la posibilidad de extubar al paciente si hubo que asegurar la vía aérea. Sin embargo, si los signos clínicos previamente nombrados no mejoran, es necesario cuestionarse la falla del tratamiento. Una herramienta útil para reevaluar al paciente es la TC postoperatoria, ya que se puede observar la obstrucción persistente de la vía aérea, el correcto vaciamiento de los espacios anatómicos o identificar la progresión de la infección hacia otros espacios vecinos.

Otra consideración importante es la identificación de alguna complicación como lo puede ser la infección rápidamente progresiva conocida como fascitis necrotizante, la cual es ocasionalmente encontrada en cabeza y cuello, frecuentemente debido a una IO o en heridas postquirúrgicas ${ }^{49}$. La Fascitis necrotizante es una infección de rápida evolución que afecta al tejido celular subcutáneo, fascia, músculo platisma y puede descender hasta la pared toráxica. La DM y el alcoholismo son considerados factores de riesgo ${ }^{49}$. La sospecha de una fascitis necrotizante es una emergencia quirúrgica que requiere la administración de un antibiótico de amplio espectro, debridaje quirúrgico repetido, eliminación del tejido necrótico y un soporte médico intensivo. La mortalidad global de la fascitis necrotizante oscila entre el 20 y el $47 \%{ }^{49}$. 
Muchas veces es difícil identificar si la falla del tratamiento fue por un inadecuado vaciamiento y drenaje de los espacios anatómicos comprometidos o por la incorrecta selección del antibiótico. En el caso de las IOs severas con compromiso de múl- tiples espacios o en pacientes con compromiso del sistema inmune se justifica el cultivo microbiano con antibiograma, el cual nos indicaría si nuestro antibiótico elegido empíricamente es efectivo contra los microbios patógenos ${ }^{8,31}$.

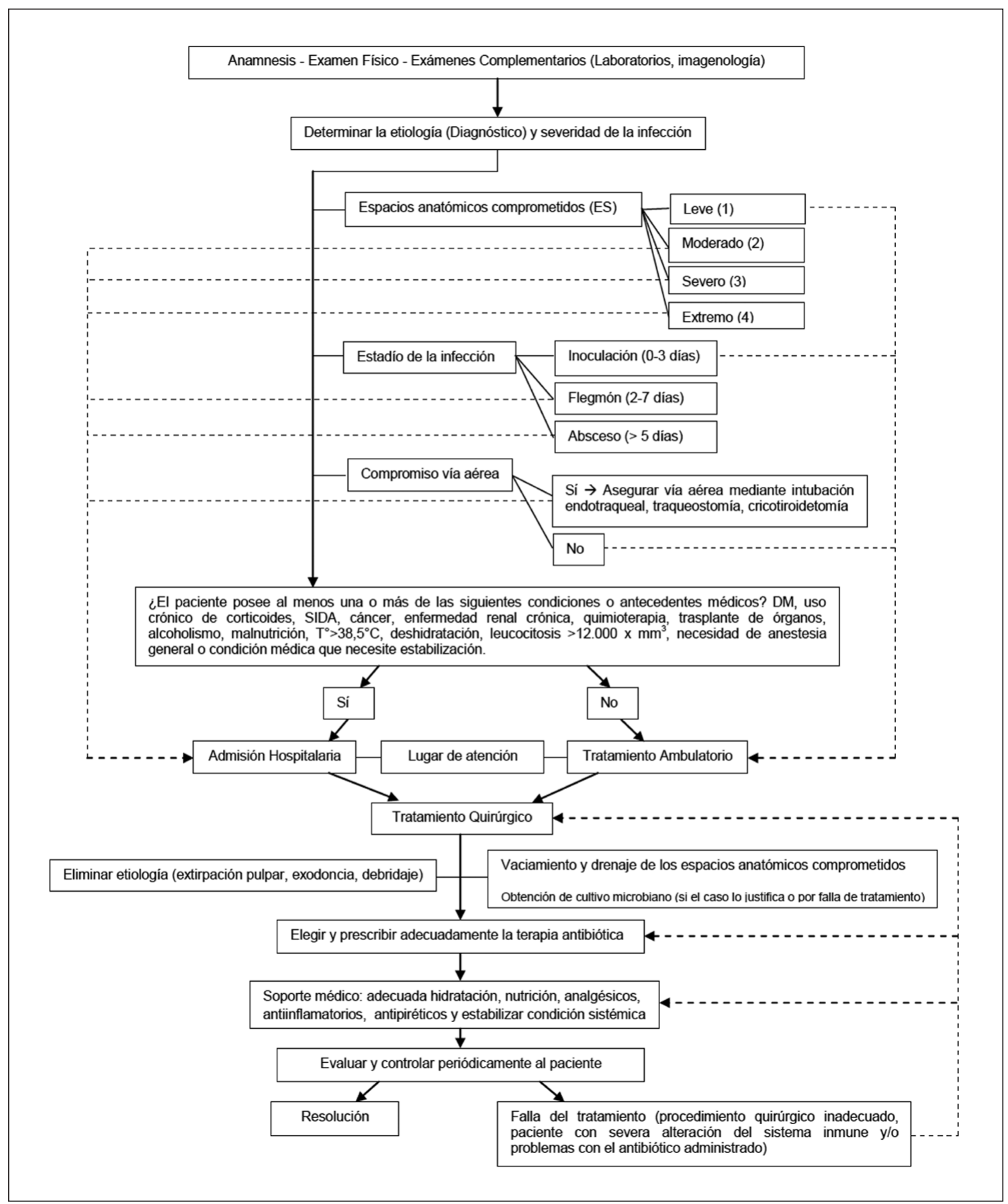

Figura 5. Algoritmo del enfoque por etapas para el tratamiento de las IOs. Las etapas se discuten en el texto. 


\section{Conclusión}

El manejo de las IOs severas pueden ser los casos clínicos más demandantes para el Odontólogo y Cirujano Maxilofacial. Los casos más complejos se presentan frecuentemente asociados con enfermedades sistémicas que afectan el sistema inmune. Además, algunos de estos casos pueden presentar una potencial obstrucción de la vía aérea, aspecto que debe ser lo primero a evaluar en las infecciones ubicadas en cabeza y cuello.

Peterson, fue el primero en establecer los principios a seguir frente a una IO severa, junto con sus recomendaciones para la admisión hospitalaria y seguridad de la vía aérea de los casos más complejos. Posteriormente, Flynn, modificó estos principios aplicando sus estudios prospectivos en IOs, estableciendo el manejo quirúrgico temprano y dando a conocer la emergente resistencia de los patógenos bucales a las penicilinas.

Hemos simplificado estos principios a 7 pasos que necesariamente deben evaluarse frente a todas las IOs y así rápidamente determinar si el paciente va a requerir una admisión hospitalaria para su tratamiento quirúrgico, estabilización médica o para asegurar una vía aérea comprometida. En base a todo lo discutido hemos sintetizado estos principios en la Figura 5. No obstante, pese a la aplicación de estos principios, siempre debe existir la posibilidad de que el tratamiento falle, ya sea por un diagnóstico errado, resistencia al antibiótico o de enfermedades sistémicas no diagnosticadas. En consecuencia, los clínicos deben mantener actualizados sus conocimientos en la cambiante microbiología, medicina interna y de las terapias antibióticas contemporáneas.

Finalmente, Peterson y Flynn, concluyen que pese a la utilización de todos estos principios no se puede asegurar el éxito del tratamiento en todos los casos, pero si abarca a cabalidad todos los factores que pueden alterar el pronóstico y que le aseguran al clínico que está realizando su tratamiento bajo los más altos estándares de cuidado.

\section{Referencias}

1. Poveda-Roda R, Bagan JV, Sanchis-Bielsa JM, Carbonell-Pastor E. Antibiotic use in dental practice: A review. Med Oral Patol Oral Cir Bucal 2007;12:186-92.

2. Clarke JH. Toothaches and death. J Hist Dent. 1999; 47:11-3

3. Williams AC. Ludwig's angina. Surg Gynecol Obstet. 1940;70:140.

4. Williams AC, Guralnick WC. The diagnosis and treatment of Ludwig's angina: a report of twenty cases. N Engl J Med.1943;228:443.
5. Huang TT, Liu TC, Chen PR, Tseng FY, Yeh TH, Chen YS. Deep neck infection; analysis of 185 cases. Deep neck infection; analysis of 185 cases. Head Neck 2004;26:854-60.

6. Amponsah E, Donkor P. Life-threatening Oro-facial infections. Ghana Med J. 2007;41:33-6.

7. Peterson LJ. Contemporary management of deep infections of the neck. J Oral Maxillofac Surg. 1993;51:22631.

8. Miloro M, Ghali G, Larsen P, Waite P. Peterson's principles of oral and maxillofacial surgery. $2^{\text {nd }}$ edition. BC Decker Inc, Hamilton. London. 2004. p. 277-93.

9. Bratton TA, Jackson DC, Nkungula-Howlett T, Williams $\mathrm{CW}$, Bennett CR. Management of complex multi-space odontogenic infections. J Tenn Dent Assoc. 2002;82:3947.

10. Miller WD, Furst IM, Sandor GKB, Keller MA. A prospective blinded comparison of clinical examination and computed tomography in deep neck infections. Laryngoscope. 1999;109:1873-9.

11. Flynn TR, Wiltz M, Adamo AK, Levy M, McKitnick J, Freeman K. Predicting length of hospital stay and penicillin failure in severe odontogenic infections. Int J Oral Maxillofac Surg. 1999;28 (Suppl 1):48.

12. Rouviere H, Delmas A. Anatomía Humana, descriptiva, topográfica y funcional. 11a Ed. Barcelona, Masson, 2005. Tomo I. p.551-628.

13. Flynn TR, Shanti RM, Levi MH, Adamo AK, Kraut RA, Trieger N. Severe odontogenic infections, part 1: prospective report. J Oral Maxillofac Surg. 2006;64:1093103.

14. Feigin RD, Cherry JD. Textbook of pediatric infectious diseases. Vol 1. 4th Ed. Philadelphia (PA). WB Saunders Co.1998.p.134-48.

15. Leibovici L, Yehezkelli Y, Porter A. Influence of diabetes mellitus and glycemic control on the characteristics and outcome of common infections. Diabet Med. 1996;13:457-63.

16. Vernillo AT. Diabetes mellitus: relevance to dental treatment. Oral Surg Oral Med Oral Pathol Oral Radiol Endod. 2001;91:263-70.

17. Cianciola LJ, Park BH, Bruck E, Mosovich L, Genco RJ. Prevalence of periodontal disease in insulin-dependent diabetes mellitus. J Am Dent Assoc. 1982;104:65360 .

18. Mattson J, Cerutis D. Diabetes mellitus: a review of the literature and dental implications. Compendium 2001;22:757-72.

19. Naghibi M, Smith R, Baltch A, Gates SA, Wu DH, Hammer MC, et al. The effect of diabetes mellitus on chemotatic and bactericidal activity of human polymorphonuclear leukocytes. Diabetic Research and Clinical Practice. 1987;4:27-35.

20. Grossi SG, Genco RJ. Periodontal disease and diabetes mellitus: a two-way relationship. Ann Periodontol. 1998;3:51-61. 
21. Lalla E, Lamster IB, Schmidt AM. Enhanced interaction of advanced glycation end-products with their cellular receptor for RAGE: implications for the pathogenesis of accelerated periodontal disease in diabetes. Ann Periodontol. 1998;3:13-9.

22. Löe H. Periodontal disease. The sixth complication of diabetes mellitus. Diabetes Care 1993;16:329-34.

23. Aslangul E, Le Jeunne C. Role of corticosteroids in infectious disease. Presse Med. 2012;41:400-5.

24. Facciabene A, Motz GT, Coukos G. T-regulatory cells: key players in tumor immune escape and angiogenesis. Cancer Res. 2012;72:2162-71.

25. Miller EJ Jr, Dodson TB. The risk of serious odontogenic infections in HIV-positive patients: a pilot study. Oral Surg Oral Med Oral Pathol Oral Radiol Endod. 1998; 86:406-9.

26. Murphy MF, Metcalfe P, Waters AH, Carne CA, Weller IV, Linch DC, et al. Incidence and mechanism of neutropenia and thrombocytopenia in patients with $\mathrm{HIV} . \mathrm{Br}$ J Haematol. 1987;66:337-40.

27. Murphy PM, Clifford LH, Fauci AS, Gallin JI. Impairment of neutrophil bactericidal capacity in patients with AIDS. J Infect Dis. 1988;158:627-30.

28. Nielsen H, Kharazmi A, Faber V. Blood monocyte and neutrophil functions in acquired immune deficiency syndrome. Scand J Immunol. 1986;24:291-6.

29. Moore RD, Keruly JC, Chaisson RE. Neutropenia and bacterial infection in acquired immunodeficiency syndrome. Arch Intern Med. 1995;155:1965-70.

30. Carey J, Dodson TB, Miller E. Hospital course of HIVpositive patients with odontogenic infections. Oral Surg Oral Med Oral Pathol. 2001;91:23-7.

31. Flynn TR, Shanti RM, Hayes C. Severe odontogenic infections, part 2: prospective outcomes study. J Oral Maxillofac Surg. 2006; 64:1104-13.

32. Flynn TR. Surgical management of orofacial infections. Atlas Oral Maxillofac Surg Clin North Am. 2000;8:77100.

33. Telford G. Postoperative fever. In: Condon RE, Nyhus LM, editors. Manual of surgical therapeutics. 6th Ed. Boston (MA). Little, Brown. 1985. p.179.

34. Mesejo Arizmendi A. Manual Básico de Nutrición Clínica y Dietética. $1^{\mathrm{a}}$ edición. Generalitat Valenciana. 2000.p.163-6.

35. Flynn TR, Halpern LR. Antibiotic selection in head and neck infections. Oral Maxillofac Surg Clin North Am. 2003; 15:17-38.

36. Robertson, D, Smith AJ. The microbiology of the acute dental abscess. J Med Microbiol. 2009;58:155-62.
37. Fazakerley MW, McGowan P, Hardy P, Martin MV. A comparative study of cephradine, amoxicillin and phenoxymethylpenicillin in the treatment of acute dentoalveolar infection. Br Dent J. 1993;174:359-63.

38. Gilmore WC, Jacobus NV, Gorbach SL, Doku HC, Tally FP. A prospective double-blind evaluation of penicillin versus clindamycin in the treatment of odontogenic infections. J Oral Maxillofac Surg. 1988;46:1065-70.

39. Lewis MA, Carmichael F, MacFarlane TW, Milligan SG. A randomised trial of co-amoxiclav (Augmentin) versus penicillin $\mathrm{V}$ in the treatment of acute dentoalveolar abscess. Br Dent J. 1993;175:169-74.

40. Paterson SA, Curzon ME. The effect of amoxicillin versus penicillin $\mathrm{V}$ in the treatment of acutely abscessed primary teeth. Br Dent J. 1993;174:443-9.

41. Kuriyama T, Karasawa T, Nakagawa K, Saiki Y, Yamamoto E, Nakamura S. Bacteriologic features and antimicrobial susceptibility in isolates from orofacial odontogenic infections. Oral Surg Oral Med Oral Pathol Oral Radiol Endod. 2000;90:600-8.

42. Kuriyama T, Karasawa T, Nakagawa K, Yamamoto E, Nakamura S. Bacteriology and antimicrobial susceptibility of gram-positive cocci isolated from pus specimens of orofacial odontogenic infections. Oral Microbiol Immunol. 2002;17:132-5.

43. Poeschl PW, Spusta L, Russmueller G, Seemann R, Hirschl A, Poeschl E, et al. Antibiotic susceptibility and resistance of the odontogenic microbiological spectrum and its clinical impact on severe deep space head and neck infections. Oral Surg Oral Med Oral Pathol Oral Radiol Endod. 2010;110:151-6.

44. Al-Qamachi LH, Aga H, McMahon J, Leanord A, Hammersley N. Microbiology of odontogenic infections in deep neck spaces: a retrospective study. Br J Oral Maxillofac Surg. 2010;48:37-9.

45. Craig TJ, Mende C. Common allergic and allergic-like reactions to mediations: when the cure becomes the curse. Postgrad Med. 1999;105:173-81.

46. Briggs G, Freeman R, Yaffe S. Drugs in Pregnancy and Lactation. 9th Revised edition edition. Lippincott Williams and Wilkins. 2011.

47. Kasten MJ. Clindamycin, metronidazole, and chloramphenicol. Mayo Clin Proc. 1999;74:825-33.

48. Gilbert DN, Moellering Jr RC, Sande MA. The Sanford guide to antimicrobial therapy. 32nd edition. Hyde Park (VT). Antimicrobial Therapy Inc. 2000.

49. Balcerak RJ, Sisto JM, Bosack RC. Cervicofacial necrotizing fasciitis: report of three cases and literature review. J Oral Maxillofac Surg. 1988;46:450-9. 